\title{
Macular profile of eyes developing macular holes in cases of central retinal vein occlusion treated with Bevacizumab
}

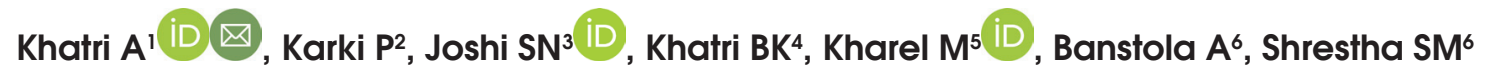

${ }^{1}$ Anadi Khatri, Vitreo-Retinal Surgeon, Birat Eye Hospital, Biratnagar, Nepal; ${ }^{2}$ Pratap Karki, Ophthalmologist; ${ }^{3}$ Sagun Narayan Joshi, Vitreo-Retinal Surgeon, BP Koirala Lions Centre for Ophthalmic Studies, Institute of Medicine, Tribhuvan University, Nepal; ${ }^{4}$ Bal Kumar Khatri (K.C.), Senior Consultant, Birat Eye Hospital, Biratnagar, Nepal; ${ }^{5}$ Muna Kharel, Resident, Department of Ophthalmology, Nepalese Army Institute of Health Sciences, Kathmandu, Nepal; ${ }^{6} \mathrm{Amrit}$ Banstola; ${ }^{6} \mathrm{Saurav}$ Man Shrestha, Ophthalmologist, Lumbini Eye Institute and Research Centre, Lumbini, Nepal.

\begin{abstract}
Background: Anti-vascular endothelial growth factors are commonly used for treatment of central retinal vein occlusion. There have been numerous reports regarding both the benefits and disadvantages of its use. Recently, a rather surprising complication- development of macular holes have started emerging.

Objectives: The purpose of this study was to evaluate if the patient's profile, baseline optical coherence tomography parameters, status of the vitreous and subsequent response pose a risk for macular hole formation in cases of central retinal vein occlusion following treatment with bevacizumab.

Methodology: This prospective exploratory analytical study was conducted at a tertiary eye care center of Nepal and evaluated 97 eyes with central retinal vein occlusion undergoing treatment with bevacizumab.

Results: Full Thickness Macular Hole developed in eight (8.24\%) of the central retinal vein occlusion eyes treated with bevacizumab. Elderly age and eyes with cystoid edema at baseline were found to have greater risk of developing macular hole following treatment (OR: $8.97, \mathrm{p}<0.05)$. Twelve $(12.3 \%)$ of the treated eyes developed vitreoretinal interface anomalies and were the result of dramatic decrease in central macular thickness. All of them had cystoid macular edema at baseline. Five of them (42\%) developed full thickness macular hole.

Conclusion: Anti-vascular endothelial growth factor agents have been widely accepted as the first line of choice for treatment of macular edema secondary to central retinal vein occlusion. Cystoid macular edema, eyes of the elderly and those showing dramatic decrease in central macular thickness with the development of anomalous vitreoretinal interface are potential risk factors for full thickness macular hole.
\end{abstract}

Key words: Bevacizumab; Central retinal vein occlusion; Cystoid macular edema; Macular hole; Vitreous detachment; Vireo-macular traction.

Access this article online

Website: www.jkmc.com.np

DOI: https://doi.org/10.3126/jkmc.v9i1.33516

HOW TO CITE

Khatri A, Karki P, Joshi S, Khatri (KC) BK, Kharel M, Banstola A, Shrestha SM. Macular profile of eyes developing macular holes in cases of central retinal vein occlusion treated with Bevacizumab. J Kathmandu Med Coll. 2020;9(1):13-19.

Address for correspondence

Dr. Anadi Khatri

Vitreo-Retinal Surgeon

Department of Vitreo-Retina Disease and Surgery

Birat Eye Hospital, Biratnagar, Nepal

E-mail: anadikc@gmail.com

Copyright $\odot 2020$ Journal of Kathmandu Medical College (JKMC)

ISSN: 2019-1785 (Print), 2091-1793 (Online)

(7) (8) This work is licensed under a Creative Commons Attribution-Non Commercial 4.0 International License.

\section{INTRODUCTION}

Central retinal vein occlusion (CRVO) is one of the most common retinal vascular disorders with potential risk of profound and permanent visual loss ${ }^{1}$. The visual prognosis of eyes with CRVO often depends on the type of retinal vein occlusion, time of presentation, severity of retinal ischemia and macular edema (ME) ${ }^{2}$. ME is a major risk factor for visual loss. ME associated with cystoid changes or chronicity (>8 months), can often lead to permanent vision loss mainly due to insult to the visual components at microscopic levels ${ }^{1,2,3}$.

ME secondary to CRVO is thought to be caused by vasculogenic or inflammatory mechanisms or both ${ }^{2}$. It was in 2005 when it was first reported that bevacizumab can successfully resolve macular edema due to retinal vein occlusion ${ }^{3}$. Since then, it has gained popularity and has been widely used as an off-label treatment for this 
pathology. It still remains a mainstay of treatment in many countries around the world ${ }^{4}$.

Anti-vascular endothelial growth factors (VEGFs) have remained the mainstay of treatment for ME of various origins and same holds true for $\mathrm{CRVO}^{2,4}$ with numerous reports available on both the benefits and disadvantages of its use $\mathrm{S}^{5,6,7,8}$. Recently, a rather surprising complicationdevelopment of full thickness macular holes (FTMH) in eyes treated with bevacizumab for ME secondary to CRVO has started being documented from various parts of the world ${ }^{9,10,11}$.

With growing evidence suggesting the possibility of development of FTMH due to anti-VEGF in CRVO, major literature reviews were analyzed ${ }^{3,4,12,13}$ which found no mentioning of such association. To our knowledge, there have only been case reports and there are no studies that has evaluated this association.

Hence, we conducted this study to evaluate the occurrence of FTMH in CRVO treated with anti-VEGF agents. We also aim to determine if a patient's profile, existing systemic pathologies, baseline optical coherence tomography parameters, status of the vitreous and subsequent response pose a risk for macular hole formation in cases of CRVO following treatment with bevacizumab.

\section{METHODOLOGY}

A prospective analytical study was conducted where we analyzed the treatment outcomes following intravitreal bevacizumab for macular edema secondary to central retinal vein occlusion. This study was conducted at a tertiary eye care center in Nepal. Since this was an exploration study, no sample size calculations were made. We enrolled consecutive cases with CRVO who presented from February 2018 to November 2018. Ninety-seven patients fitting the inclusion criteria were included in the study.

The diagnosis of CRVO was based clinically after fundus examination and Fundus Fluorescence angiography (FFA). The research protocol was approved by the local ethics committee of Birat Eye hospital (BH/R/018/C05) and adhered to the tenets of the Declaration of Helsinki. All patients included in the study received central macular scan using the automated software in the 31line raster scan pattern. Central macular thickness was measured at baseline and in subsequent follow-ups after each dose of bevacizumab using the built-in caliper at follow-ups of four weeks. All scans were interpreted by two experienced vitreoretinal surgeons.

The macular edema was classified as cystoid and noncystoid. Criteria to label cystoid macular edema was adopted from the American Academy of Ophthalmology preferred Practice Patterns-which defines cystoid macular edema (CME) as retinal thickening of the macula due to disruption of normal blood-retinal barrier and accumulation of fluid within the intracellular spaces of the retina, primarily in the outer plexiform layer ${ }^{13}$.

The inclusion criteria for this study consisted of newly diagnosed cases with macular edema due to CRVO and were treated initially with monthly bevacizumab. Patients who had any of the following therapy in the study eye either prior to or during the initial three anti-VEGF injections were excluded: focal/grid laser photocoagulation, pan-retinal photocoagulation (PRP) or peri/ intravitreal injections (e.g. intravitreal or subtenon's injections of corticosteroids). Patients were also excluded if they had any of the following concomitant ocular diseases: diabetic macular edema, age-related macular degeneration, prior ocular surgery (except cataract surgery), pre-existing abnormal vitreoretinal interface, lamellar or full thickness macular hole and choroidal neovascularization.

The preparation of bevacizumab was done using a standard aseptic procedure to partition the doses from the vial $(100 \mathrm{mg} / 4 \mathrm{~mL})$ into $1 \mathrm{~mL}$ tuberculin syringes containing $0.05 \mathrm{~mL}$ of bevacizumab. The drug was injected using a standard aseptic convention, including the utilization of a topical analgesic, povidone-iodine scrubbing and a sterile speculum. Bevacizumab was injected into the vitreous through the pars plana 3.5 to $4 \mathrm{~mm}$ posterior to the limbus using a sterile 30-gauge needle. If necessary, the injection was repeated at four weeks again. Recorded outcome measurements include the best-corrected visual acuity assessment with the Early Treatment Diabetic Retinopathy Study chart ${ }^{8}$ and the central sub-field macular thickness (CSMT) measurement of the treated eyes at four weeks after the injections. The results were analyzed using Statistical Package for the Social Sciences (SPSS) software (Ver 20.0). The mean, standard deviation, confidence interval (C. I), odds ratio and Fishers' exact test were used to calculate the associated risk. p-value of $<0.05$ were considered statistically significant. 


\section{RESULTS}

A total of 97 eyes of 97 patients diagnosed with CRVO were included in this study. Fifty-seven (58.8\%) were males. The mean interval of symptoms to presentation at the clinic was 4.1 days \pm 1.6 days. There were forty six eyes with cystoid macular edema $(47.1 \%)$ The CMT for eyes with edema was 706 66 microns. Demographics and baseline clinical characteristics of the patients are reported in Table 1.

\section{AGE AND MACULAR THICKNESS AS RISK FACTORS}

Eight (8.24\%) of the CRVO eyes treated with anti-VEGF injections developed full-thickness macular hole (FTMH). The mean interval from treatment when the FTMH formed was 42.9 days with a mean dose of 1.7 injections. The mean age of patients with macular holes was $64.9 \pm$ 11.3 years in contrast to patients not developing macular hole who had a mean age of $56.6 \pm 8.9$ years $(p=0.030)$ by the end of the study. The eyes developing FTMH had mean baseline CMT baseline of $665 \pm 82$ microns, which was significantly higher than eyes with non-cystoid edema $536 \pm 38(p<0.05)$.

\section{CYSTOID MACULAR EDEMA (CME) AS A RISK FACTOR}

Seven out of eight eyes (87.5\%) developing macular hole had edema which was cystoid in nature at presentation (OR 9.97, $p=0.0031$ ). Table 2 illustrates the event of FTMH with type of macular edema. Vitreoretinal interface anomaly due to exaggerated response as a risk factor

Twelve eyes developed anomalous VRI after receiving bevacizumab (Figure 1). All of them had cystoid macular

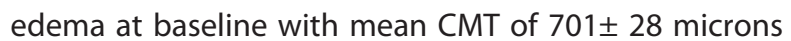
(95\% Cl for mean $p<0.05,665$ to 739 microns). None of the eyes when initially evaluated before treatment had vitreomacular traction (VMT) or Vitreous detachment (VD.)

The peculiarity of this finding was that the average response after a single dose of bevacizumab in this group was $379.8 \pm 42$ microns $(95 \% \mathrm{Cl}$ for mean $p<0.05$, 321 to 387 microns ) compared to other eyes which had an average response of $118.3 \pm 47$ microns ( $(95 \% \mathrm{Cl}$ for mean $p<0.05), 71$ to 121 microns) with an average duration from treatment to detection being $32.3 \pm 5.4$ days.

Five out of these 12 eyes (42\%) developing anomalous VRI developed FTMH (Figure 2 and Figure 3) with four of them developing it by the time of their second treatment schedule (mean duration - 34.4 days) One eye developed FTMH with VMT after second injection of bevacizumab on $51^{\text {st }}$ day.

Table 1: Demographic Profile and baseline parameters of the eyes evaluated

\begin{tabular}{|c|c|c|}
\hline Baseline Characteristics & \multicolumn{2}{|c|}{ CRVO ( $\mathrm{N}=97$ eyes from 97 patients) } \\
\hline \multicolumn{3}{|l|}{ AGE } \\
\hline Mean (SD) & \multicolumn{2}{|c|}{$60.4(7.13)$} \\
\hline Median (min, max) & \multicolumn{2}{|c|}{$61.0(46,73)$} \\
\hline \multicolumn{3}{|l|}{ Gender } \\
\hline Male & \multicolumn{2}{|c|}{$57(58.8 \%)$} \\
\hline Female & \multicolumn{2}{|c|}{$40(41.2 \%)$} \\
\hline Visual Acuity in study eye (in Log MAR) & Baseline & Follow-up \\
\hline $\begin{array}{l}\text { Mean (SD) } \\
(95 \% \mathrm{Cl} \text { for mean } \mathrm{p}<0.05)\end{array}$ & $1.07 \log$ MAR (0.987 to $1.23 \log$ MAR) & $\begin{array}{c}0.91 \log \text { MAR } \\
\text { (0.867 to } 0.936 \log \text { MAR) }\end{array}$ \\
\hline Baseline CMT (microns) in study eye & Baseline & Follow-up \\
\hline Mean (SD) & $645(202)$ & $324(103)$ \\
\hline $95 \% \mathrm{Cl}$ for mean $\mathrm{p}<0.05$ ) & (574 to 698$)$ & (297 to 436$)$ \\
\hline $\begin{array}{l}\text { Mean CMT of the eyes with cystoid edema } \\
95 \% \text { CI for mean } \mathrm{p}<0.05 \text { ) }\end{array}$ & $\begin{array}{c}706(66) \\
(679 \text { to } 735)\end{array}$ & $\begin{array}{c}439(102) \\
(382 \text { to } 589)\end{array}$ \\
\hline $\begin{array}{l}\text { Mean CMT of the eyes with non-cystoid edema } \\
95 \% \text { CI for mean } \mathrm{p}<0.05 \text { ) }\end{array}$ & $\begin{array}{c}536(38) \\
\text { (495 to } 543)\end{array}$ & $\begin{array}{c}313(94) \\
\text { (224 to } 397)\end{array}$ \\
\hline
\end{tabular}


Khatri $A$ et al.

Table 2: Risk of macular hole in eyes with cystoid macular edema

\begin{tabular}{|c|c|c|c|c|}
\hline \multirow{2}{*}{\multicolumn{2}{|c|}{ Parameters / (Total Eyes with CRVO $n=97)$}} & \multicolumn{2}{|c|}{ Macular hole } & \multirow{2}{*}{ Total } \\
\hline & & YES & NO & \\
\hline \multirow{2}{*}{$\begin{array}{l}\text { Cystoid Macular } \\
\text { edema(CME) }\end{array}$} & Present & 7 & 39 & 46 \\
\hline & Absent & 1 & 50 & 51 \\
\hline \multicolumn{2}{|l|}{ Total } & 8 & 89 & 97 \\
\hline \multirow{2}{*}{\multicolumn{2}{|c|}{ Risk Estimation }} & \multirow{2}{*}{ Value } & \multicolumn{2}{|c|}{ 95\% Confidence interval } \\
\hline & & & Lower & Upper \\
\hline \multicolumn{2}{|c|}{ Odds Ratio for severity CME(YES / NO) } & 8.97 & 1.05 & 16.0 \\
\hline \multicolumn{2}{|c|}{ Number of total cases ( $n$ ) } & 97 & & \\
\hline \multicolumn{2}{|l|}{ Significance level } & $p=0.0441$ & & \\
\hline
\end{tabular}

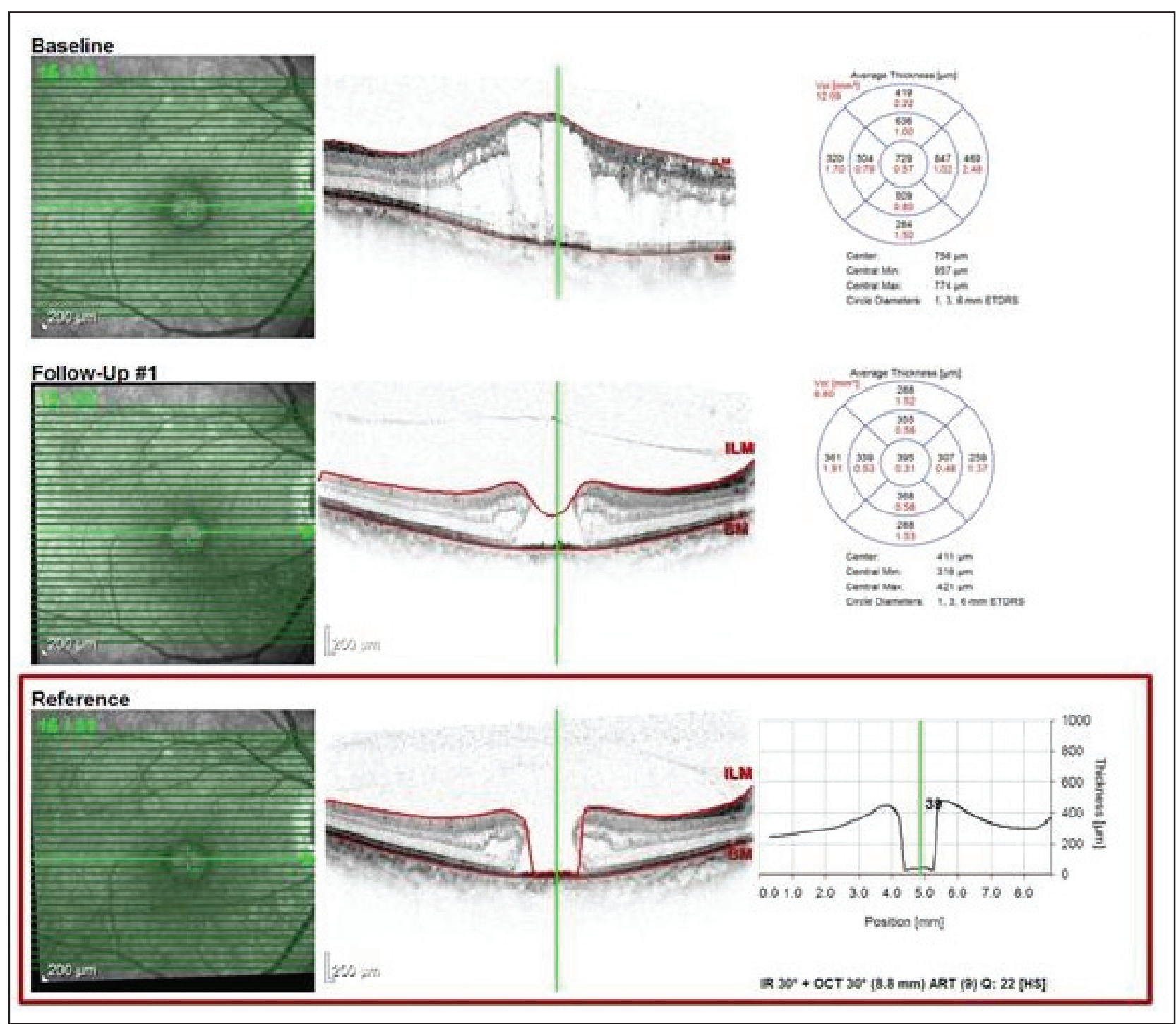

Figure 1: OCT images of a patient with CRVO and macular edema who was treated with bevacizumab. Note the pathology progressing towards macular hole 


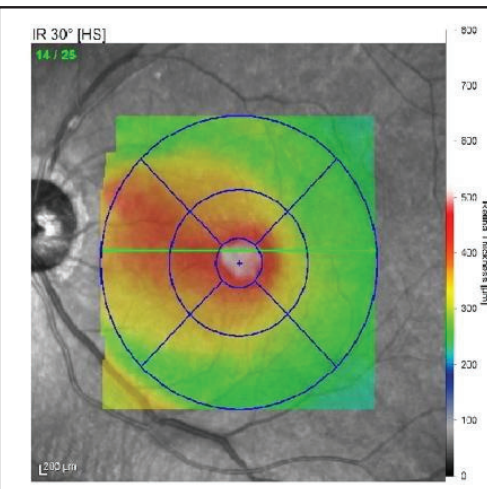

OCT $20^{\circ}(5.0 \mathrm{~mm})$ ART (10) Q: 17 [HS]

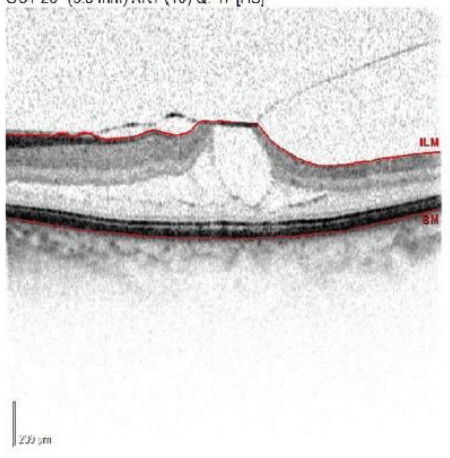

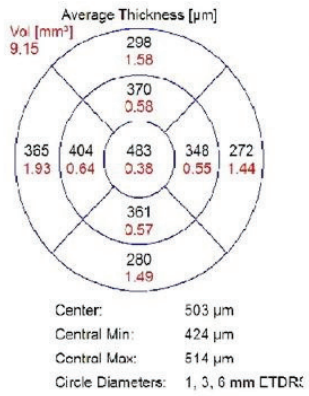

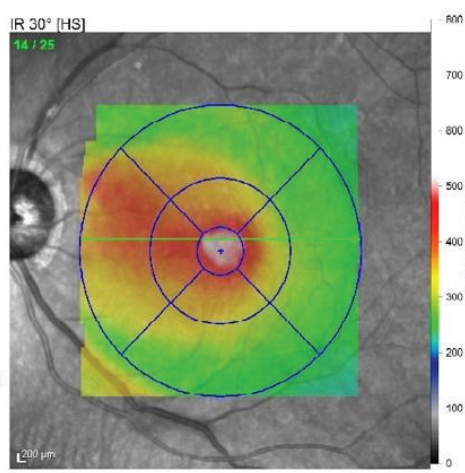

Vol [mmn
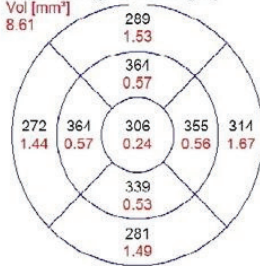

Center: $\quad 203 \mathrm{\mu m}$

Central Min: $\quad 115 \mu \mathrm{m}$

Central Max: $\quad 441 \mu \mathrm{m}$

Circle Diameters: $1,3,6$ mm ETDRS
OCT 20" $(6.0 \mathrm{~mm})$ ART (10) Q: 17 IHSI

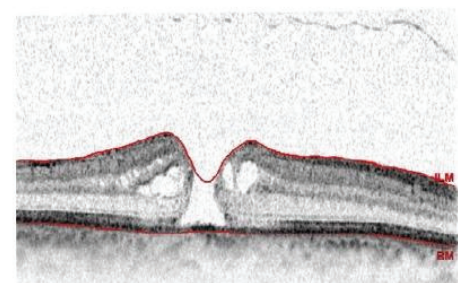

$200=11$

Figure 2: OCT of a patient who developed vitreo-macular traction followed by full thickness macular hole after treatment

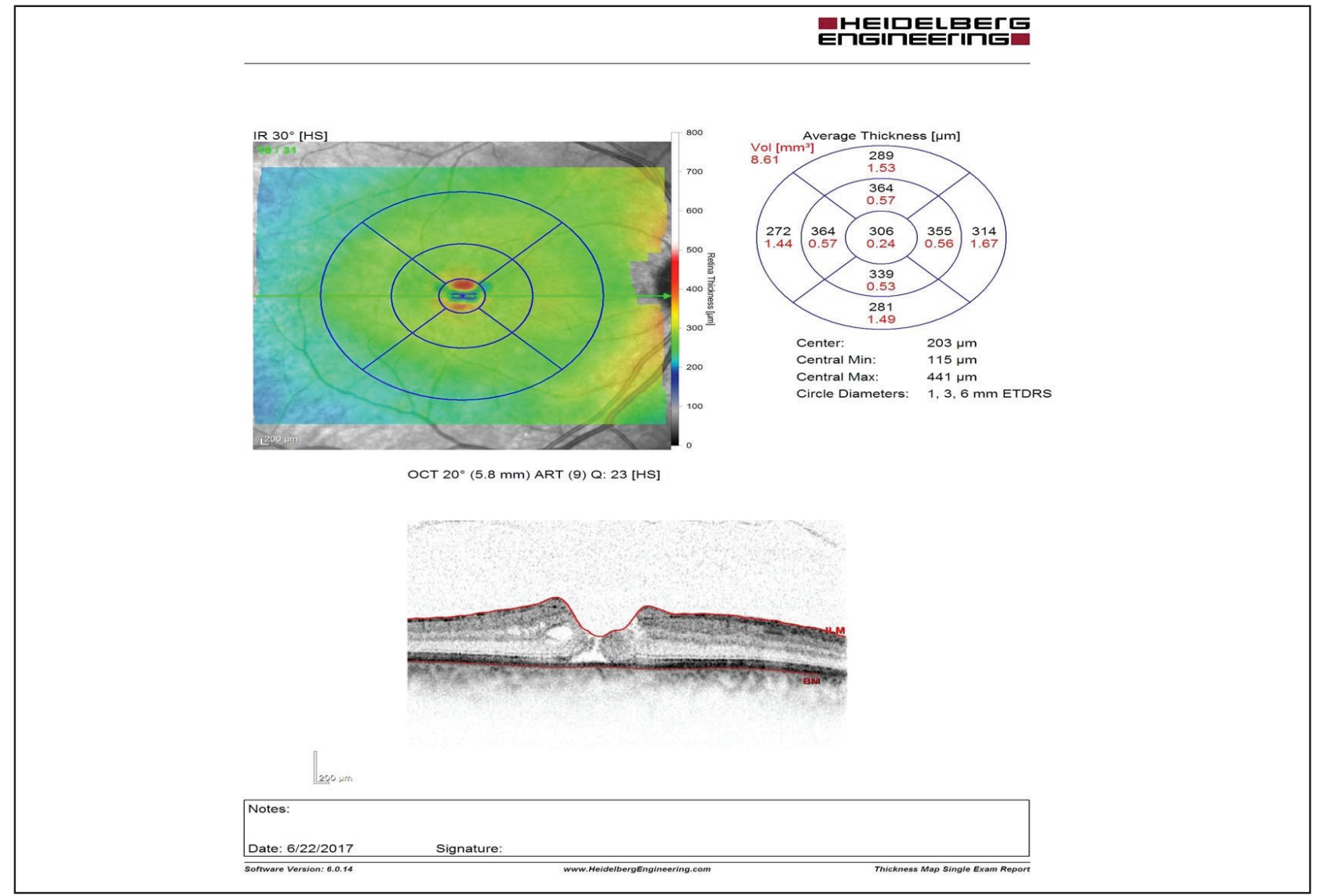

Figure 3: OCT of a patient who developed full thickness macular hole with release of vitreo-macular traction after treatment with bevacizumab 


\section{DISCUSSION}

Bevacizumab is widely accepted as an initial treatment for ME secondary to CRVO. Many of the adverse effects have also been documented and reported in various studies ${ }^{7}$, 14, 15 but very few literature can be found regarding the formation of full-thickness macular holes in eyes treated for ME due to CRVO $9,10,11$.

Our study highlights that the chance of development of FTMH in CRVO after treatment with bevacizumab cannot be neglected as nearly $8 \%$ of all patients developed it. Patients developing CRVO at elderly age, having predominantly cystoid macular edema, and developing anomalous VRI as a result of possible exaggerated response during the course of treatment were found to be at higher risk of developing FTMH.

Maximum patients developed FTMH specially around the time when the second intravitreal injection was scheduled. Hence, treating ophthalmologists must focus on the findings we have mentioned above in those patients while planning for further treatment.

Our study also found out that more than $40 \%$ of the eyes with exaggerated responses to anti-VEGF went on to develop anomalous VRI. VMT- although known to be a risk for $\mathrm{MH}$ in various pathologies ${ }^{16,17,18}$, to our knowledge, its association has not been mentioned with CRVO or its treatment. Our study is the first of its kind

\section{REFERENCES}

1. Coscas G, Gaudric A. Natural course of non aphakic cystoid macular edema. Surv Ophthalmol. 1984;28(Suppl):471-84. [DOI]

2. Cho $H$, Madu A. Etiology and treatment of the inflammatory causes of cystoid macular edema.J Inflamm Res. 2009;2:37-43. [DOI]

3. Rosenfeld PJ, Fung AE, Puliafito CA. Optical coherence tomography findings after an intravitreal injection of bevacizumab (avastin) for macular edema from central vein occlusion. Ophthalmic Surg Lasers Imaging. 2005 Jul-Aug;36. PMID: 16156153 [PubMed]

4. Manayath GJ, Narendran V, Al-Kharousi N, Wali UK. Bevacizumab therapy for macular edema in central retinal vein occlusion: Long-term results. Oman J Ophthalmol. 2009 Jun;2(2):73-8. [DOI]

5. Khatri A, Karki P, Joshi SN, Sitaula RK. Evaluation of effect of bevacizumab on central subfield macular thickness in the injected and contralateral (untreated) eye of patients with bilateral diabetic to report a possible relation by illustrating that patients with CME who develop VMT could be at higher risk of developing FTMH. Such patients could be labelled as "High Risk for FTMH" and may require closer observation.

The major limitation of the study is that this is an exploratory study and hence the sample size is very small. It is also conducted in a single center and is regionspecific. While bevacizumab is still the accepted antiVEGF for ophthalmic purposes in Nepal given its relatively cheaper cost and availability, other anti-VEGF molecules have been developed and are available. While larger study is a major recommendation for future studies, it is also necessary to evaluate if this complication can be prevented with use of newer anti-VEGF. This may further aid in better understanding if the complication is more relatable to the pathology or the drug.

\section{CONCLUSION}

Our study highlights FTMH development may be associated with treatment with anti-VEGF in certain groups of patients who demonstrate key pre-treatment and post-treatment features. Elderly age, a dramatic change in central macular thickness (CMT), CME and anomalous VFI are potential risks or indicators of FTMH formation later on the course and should be approached with caution.

Conflict of interest: None Source(s) of support: None

macular oedema.BMJ Open Ophthalmology. 2017 Dec;2:e000102. [PubMed]

6. The Diabetic Retinopathy Study Research Group. Photocoagulation treatment of proliferative diabetic retinopathy: Clinical application of Diabetic Retinopathy Study (DRS) findings, DRS Report Number 8. Ophthalmology.Jul 1981;88(7):583-600. PMID: 7196564 [PubMed]

7. Tolentino M. Systemic and ocular safety of intravitreal anti-VEGF therapies for ocular neovascular disease. SurvOphthalmol. Aug 2011;56:95-113. [DOI]

8. Guidelines for Diabetic Eye Care.The International Council of Ophthalmology (ICO) [Full Text]

9. Georgalas I, Rouvas A, Kotsolis A, Karagiannis D, Ladas I. Full Thickness Macular Hole Formation in a Patient with Cystoid Macular Edema Caused by CRVO Treated with Intravitreal Bevacizicumab. Ophthalmic Surg Lasers Imaging Retina. 2011 Mar. [DOI]

10. Nagpal M, Mehta V, Nagpal K. Macular hole progression after intravitreal bevacizumab for 
hemicentral retinal vein occlusion. Case Rep Ophthalmol. 2011 Jan. [DOI]

11. Muramatsu D, Mitsuhashi R, Iwasaki T, Goto H, Miura M. Macular hole formation following intravitreal injection of ranibizumab for branch retinal vein occlusion: a case report. BMC Res Notes. 2015 Aug;8(1):358. [DOI]

12. Falavarjani KG, Nguyen QD. Adverse events and complications associated with intravitreal injection of anti-VEGF agents: a review of literature. Eye. 2013 May;27(7):787-94. [DOI]

13. Gonzalez S, Rosenfeld PJ, Stewart MW, Brown J, Murphy SP. Avastin doesn't blind people, people blind people. Am J Ophthalmol. 2012;153(2):196203. [DOI]

14. Wen JC, McCannel CA, Mochon AB, Garner OB. Bacterial dispersal associated with speech in the setting of intravitreous injections. Arch Ophthalmol. 2011 Dec;129(12):1551-4. [DOI]
15. Evans JR, Schwartz SD, McHugh JD, Thamby-Rajah Y, Hodgson SA, Wormald RPL et al. Systemic risk factors for idiopathic macular holes: a case-control study. Eye. 1998 Mar;12:256-9. [DOI]

16. The Eye Disease Case-Control Study Group. Risk factors for idiopathic macular holes. Am J Ophthalmol. 1994 Dec;118:754-61. PMID: 7977602 [PubMed]

17. Shah SP, Bunce C, Johnston RL, Laidlaw DAH. Are biometric parameters a risk factor for idiopathic macular hole formation? Results of a matched casecontrol series. Br J Ophthalmol. 2006;90:117-8. [Full text]

18. Wong $Y$, Steel DHW, Habib MS, Stubbing-Moore A, Bajwa D, Avery PJ et al. Vitreoretinal interface abnormalities in patients treated with ranibizumab for diabetic macular oedema. Graefe's Arch Clin Exp Ophthalmol. 2017;255: 733. [DOI] 